\title{
PROMOÇÃO DA AUTOCOMPOSIÇÃ̃ NOS CONFLITOS COM A ADMINISTRAÇÃO PÚBLICA E A LEI 13.140/2015
}

\author{
Aléxia Domene Eugenio* \\ Rozane da Rosa Cachapuz**
}

Resumo: A autocomposição é forma de solução de conflitos em que o resultado é alcançado pelas próprias partes, trazendo benefícios no índice de satisfação, nos custos, na celeridade e no menor formalismo. A Administração Pública, que age para atender os interesses da coletividade, deve também poder usufruir desses benefícios. O advento da Lei 13.140/2015, a Lei de Mediação, foi essencial, mesmo que possa ser aperfeiçoada. Utiliza-se o método dedutivo para analisar legislação e doutrina referentes ao tema, com foco no estímulo à autocomposição pela nova ordem processual, e as previsões da Lei de Mediação nos conflitos com a Administração Pública.

Palavras-chave: Mediação; Autocomposição; Administração Pública; Regulamentação Legal; Interesse Público.

\section{PROMOTION OF AUTOCOMPOSITION IN CONFLICTS WITH THE PUBLIC ADMINISTRATION AND THE LAW 13.140/2015}

\begin{abstract}
Auto-composition is a form of dispute resolution in which the result is reached by the parties themselves, bringing benefits in satisfaction, costs, celerity and less formalism. The Public Administration, which acts to serve the interests of collectivity, must be able to enjoy these benefits as well. The advent of the Law 13.140/2015, the Mediation Law, was essential, even if it can be improved. The deductive method is used to analyze legislation and doctrine related to the subject, focusing on the stimulus to auto-composition in the new procedural order, and provisions of the Mediation Law in disputes with the Public Administration.
\end{abstract}

Keywords: Mediation; Auto-Composition; Public Administration; Legal Regulation; Public Interest.

\section{INTRODUÇÃO}

\footnotetext{
* Mestranda em Direito Negocial pela Universidade Estadual de Londrina. Especialista em Direito Constitucional pela Faculdade Internacional Signorelli. Pesquisa vinculada ao Projeto de Pesquisa "Os meios consensuais de resolução de conflitos e o novo CPC". E-mail: alexiadomene@gmail.com

** Doutora em Direito de Família pela Pontifícia Universidade Católica de São Paulo. Mestre em Direito Negocial pela Universidade Estadual de Londrina. Coordenadora do Projeto de Pesquisa. E-mail: rozane_cachapuz@hotmail.com
} 
Com o advento do novo Código de Processo Civil em 2015, observou-se a valorização dos meios alternativos de solução de conflito, previstos nas normas fundamentais do Código, no art. $3^{\circ}$, e disseminados ao longo do texto. No mesmo ano, houve o advento da Lei 13.140/2015, conhecida como Lei de Mediação, cuja regulamentação tem o objetivo de conferir maior segurança e respaldo legal ao uso do método. Entre as matérias trazidas no Código de Processo Civil e Lei de Mediação, está a autocomposição para a Administração Pública.

É de extrema relevância colocar em pauta a possibilidade de autocomposição dos conflitos em que as pessoas jurídicas de Direito Público são parte, visto que os problemas de duração do processo, custos e formalismo do modelo tradicional de heterocomposição judicial também os afetam de forma negativa. Abre-se uma porta para que a solução advenha das próprias partes envolvidas, e não mais simplesmente do órgão jurisdicional que historicamente substituía a vontade das partes e, de forma imperativa, impunha o modo de encerrar o litígio.

Realiza-se uma análise evolutiva dos meios alternativos de solução de conflito, especialmente pela aceitação da autocomposição como meio eficaz, superando obstáculos culturais e estruturais. Para tanto, o trabalho elenca os principais exemplos da sua regulamentação, tanto geral, através da política pública institucionalizada pelo Conselho Nacional de Justiça com a Resolução n. 125/2010, sendo depois celebrada no novo Código de Processo Civil e na Lei de Mediação que sobrevieram em 2015; como a regulamentação própria que existe a respeito da Administração Pública.

Por meio dessa análise, empregou-se o método dedutivo, para enfim compatibilizar a solução consensual de conflitos como meio adequado à participação da Administração Pública, com base numa pesquisa bibliográfica atualizada com a nova legislação e codificação processual, cujo referencial teórico são doutrinadores e processualistas brasileiros, em conjunto com as normativas existentes sobre a temática.

\section{A EVOLUÇÃo dA AUTOCOMPOSIÇÃo COMO UM EFICAZ MEIO ALTERNATIVO DE SOLUÇÃO DE CONFLITO}

Historicamente, sempre se colocou a jurisdição como o meio mais adequado e eficaz para a solução dos conflitos, sendo o processo judicial o "método institucional de solução de controvérsias" (MEDINA, 2017, p. 37). A função estatal de solução de conflitos, entretanto, 
resultou na construção do mito do puro monopólio da jurisdição, como se fosse a única via em que se obteria uma solução legítima, o que é rotulado como a "cultura do litígio judicial" (RANGEL, 2017, p. 259).

Com efeito, a realidade processual sempre esteve voltada à judicialização, cuja consequência é atingir a desejada pacificação social, como colocam Marinoni, Arenhart e Mitidiero, isso está ligado a três questões: o exercício do poder do Estado gerava segurança ao eliminar a solução privada e arbitrária; estar perante o Judiciário limita o debate e o agravamento do problema; além disso, impede que o vencido tente rediscutir a questão já decidida, dado que a decisão judicial é imperativa (2017, p. 89).

Ao mesmo tempo, o exercício da jurisdição impede a "justiça pelas próprias mãos", de acordo com Alexandre Freitas Câmara (2017, p. 41), vedando e reprimindo a autotutela, visto que o ordenamento criminaliza a conduta e busca disponibilizar instrumentos para satisfazer os interesses e pretensões resistidas.

Contudo, a judicialização não se mostra tão eficaz e adequada quanto idealmente se propôs, já que o modelo de jurisdição estatal vem sofrendo um inchaço com o aumento nas demandas, na duração do processo e na satisfação das partes, que se desgastam num embate que se prolonga no tempo.

Justamente, é a litigiosidade excessiva que tem provocado alterações significativas nos modelos de prestação jurisdicional.

Isso fica claro desde a obra de Mauro Cappelletti e Bryant Garth, sobre o acesso à justiça, apontando os obstáculos existentes e as possíveis soluções práticas, que incluem meios alternativos de solução de conflito, bem como modificações na própria tutela jurisdicional, como criação de ritos mais céleres e informais e implementação de políticas de assistência judiciária. Dividindo as soluções em três “ondas”, os “ADR - Alternative Dispute Resolution", ou métodos alternativos de solução de conflito, fazem parte da terceira onda de mudanças (1988, p. 72).

É possível classificar tais métodos entre autocompositivos e heterocompositivos, levando em consideração a forma de obtenção da solução. Os métodos heterocompositivos caracterizam-se pela existência da figura de um terceiro, que substitui a vontade das partes e impõe uma decisão que é imperativa, sendo que a arbitragem é a forma alternativa por excelência, e a solução judicial é o método heterocompositivo institucional.

Os meios autocompositivos, por sua vez, valorizam a autonomia e a vontade das partes, cujo resultado advém de conciliação, em que há um terceiro interveniente ou mediação, com a 
participação de um terceiro para reestabelecer o diálogo das partes. A respeito dos métodos autocompositivos, importante destacar que nem sempre há um terceiro facilitador, sendo possível a negociação - Augusto Neves Dal Pozzo e Ana Cristina Fecuri denominam de “consenso direto" (2017, p. 241) -, a qual é facilmente identificável na Administração Pública com a celebração de Termo de Ajustamento de Conduta - TAC, segundo Luciane Moessa de Souza e Cristina Ayoub Riche (2016, p. 177).

Sobre os benefícios dos "novos" métodos de composição de litígio, Humberto Theodoro Júnior explica (2015, p. 43):

Fala-se, nesse sentido, na criação de novas vertentes para certos tipos de prestação jurisdicional, que enriqueceriam o processo com instrumentos capacitados a realizar a justiça que Cappelletti chama de coexistencial.

Em lugar de contar apenas com a força da autoridade legal do juiz, as partes poderiam, muitas vezes, obter melhores resultados na solução de seus conflitos, recorrendo à experiência e à técnica de pessoas capacitadas a promover a mediação e a conciliação, e chegando, assim, a resultados práticos mais satisfatórios do que os decretados pela justiça tradicional.

Em um breve apanhado histórico, não é nenhuma novidade a autocomposição na resolução de conflitos. A retrospectiva das Constituições brasileiras já mostra que na própria Constituição Imperial de 1824 já havia a previsão de uma tentativa de conciliação, "exigindo que fosse tentada antes de todo o processo, como requisito para sua realização e julgamento da causa" (GRINOVER, CINTRA, DINAMARCO, 2015, p. 49).

Considera-se, entretanto, como marco do seu reconhecimento, a experiência americana, que evoluiu muito a prática de resolução de conflitos de forma alternativa. Especialmente, dá-se os holofotes à expressão cunhada por Frank Sander, que é professor emérito da Faculdade de Direito de Harvard: Tribunal Multiportas, em 1976, na Pound Conference, uma conferência que ocorreu em Minnesota naquele ano, tendo sido convidado a palestrar pelo presidente da Suprema Corte dos Estados Unidos à época, Warren Burger (ALMEIDA, R., ALMEIDA, T., CRESPO, 2012, p. 31-32).

Com o passar do tempo, outras barreiras foram rompidas, tanto em outros países como no Brasil desde a Constituição Federal de 1988. Um dos paradigmas quebrados aqui é a autocomposição em matéria penal, pois os Juizados Especiais Criminais, através da Lei 9.099/1995, permitem a conciliação para composição dos danos (art. 73) e a transação penal (GRINOVER, CINTRA, DINAMARCO, 2015, p. 49). A conciliação, na realidade, está 
presente por toda a Lei dos Juizados Especiais (Lei 9.099/1995), desde seu art. $1^{\circ}$, orientando todo o processo, seja ele de natureza cível ou criminal.

Ademais, tem-se a Lei de Arbitragem (Lei 9.307/1996), recentemente revisada pela Lei 13.129/2015 e também a Consolidação das Leis do Trabalho (Decreto-Lei n. 5.452, de $1^{\circ}$ de maio de 1943) em seu art. 846 e seguintes, sendo a tentativa de conciliação indispensável etapa da audiência na reclamação trabalhista.

Pode-se dizer que a mediação foi disciplinada pela primeira vez de forma específica pela Resolução n. 125 de 2010 do Conselho Nacional de Justiça, em razão de ainda não possuírem nenhuma regulamentação única sobre a técnica antes desse ato normativo do órgão (POZZO, FECURI, 2017, p. 241). Referida Resolução teve como base fundamental o acesso à Justiça, previsto no art. $5^{\circ}$, inciso XXXV, da Constituição Federal, e a necessidade de haver meios adequados de tratar os conflitos de interesses, que impõe o incentivo e estruturação dos mecanismos consensuais de solução de conflito - inspirando-se em Cappelletti e Garth (1988, p. 8), a Resolução 125 reconhece que o acesso à justiça "além da vertente formal perante os órgãos judiciários, implica acesso à ordem jurídica justa” (2010).

Muito embora tenha representado grande passo na política judiciária, trata-se de ato normativo da competência do CNJ, e seria preciso que o Poder Legislativo reconhecesse a necessidade da implantação das técnicas alternativas, sedimentando essa importante mudança.

\subsection{O Código de Processo Civil de 2015 e a Celebração dos Meios Alternativos de Solução de Conflito}

Ao observar o novo Código de Processo Civil, já não se pode negar que há preferência por meios alternativos de solução de conflitos, pois o diploma celebra a conciliação, mediação e arbitragem em seu art. $3^{\circ}$, entre suas normas fundamentais, bem como impondo deveres como no art. 174 e modificando outros institutos, como a audiência do art. 334.

Em que pese o trabalho foque na Lei 13.140/2015, Alexandre Freitas Câmara explica a importância de se fazer uma análise conjunta entre ela e o Código de Processo Civil, uma vez que cada um terá um objeto distinto (2017, p. 110):

Ao Código de Processo Civil incumbe regular o modo como a conciliação e a mediação se desenvolvem dentro de processos judiciais já instaurados (conciliação e mediação endoprocessuais). Evidentemente, não é preciso que 
haja processo instaurado para que se promova a solução consensual do conflito, mas da conciliação e da mediação pré-processuais não deve tratar a lei processual.

A Lei 13.140/2015 trata preponderantemente da mediação extrajudicial, com alguns aspectos de mediação judicial ${ }^{1}$, enquanto o Código prevê a mediação no curso do processo de forma mais extensa, em cada etapa do rito, com especificidades nos procedimentos especiais como nas ações de família (art. 694), nos litígios coletivos por posse de imóvel (art. 565) -, enfim, havendo relação de complementação e diálogo entre os diplomas.

José Miguel Garcia Medina (2017, p. 34), ao mesmo tempo, pontua que a Lei 13.140/2015 pode ser considerada posterior e especial, mas que como o Código também possui regras especiais acerca da mediação judicial, a aplicação de alguns dispositivos da Lei de Mediação - o autor cita os arts. 11 a 13 e 24 a 29 - dependeriam de interpretação conjunta, através do diálogo das fontes, já que os critérios tradicionais não são capazes de sanar tal dúvida.

Ao proceder a essa análise, destaca-se nas normas fundamentais do Código de Processo Civil uma forte enunciação:

Art. $3^{\circ}$. Não se excluirá da apreciação jurisdicional ameaça ou lesão a direito. $\S 1^{\circ}$. É permitida a arbitragem, na forma da lei.

$\S 2^{\circ}$. O Estado promoverá, sempre que possível, a solução consensual dos conflitos.

$\S 3^{\circ}$. A conciliação, a mediação e outros métodos de solução consensual de conflitos deverão ser estimulados por juízes, advogados, defensores públicos e membros do Ministério Público, inclusive no curso do processo judicial.

É importante transcrever o art. $3^{\circ}$ e assimilar a relação entre o caput e seus parágrafos. Na técnica legislativa, o parágrafo está intimamente relacionado com o assunto do artigo, sendo que dá os contornos, explicação ou limites necessários para a compreensão do caput (FERREIRA, 1986, p. 179).

A princípio, observa-se que o caput prevê uma reafirmação do acesso à justiça e da inafastabilidade da jurisdição (garantia fundamental insculpida no art. $5^{\circ}$, inciso XXXV, da Constituição Federal). Em seguida, em seus parágrafos trazem as formas alternativas de solução de conflito, como desdobramento, uma assertiva que são próprias vertentes do acesso à justiça, solidificando o emprego das técnicas alternativas como parte inerente do processo.

\footnotetext{
1 A doutrina também intitula a mediação "judicial” como endoprocessual (CÂMARA, 2017, p. 110), e a "extrajudicial" como extraprocessual, pois o método apenas é realizado durante o processo ou fora dele, não tendo nenhuma relação com a atividade judicial.
} 
Deve-se compreender, portanto, que a tutela adequada dos direitos não significa sempre o manejo tradicional do processo, “o conflito deve ser tratado com a técnica processual mais apropriada às suas peculiariedades - que inclusive podem determinar o recurso à jurisdição como ultima ratio.” (MARINONI, ARENHART, MITIDIERO, 2017, p. 136). Dessa forma, os meios alternativos de solução de conflitos são encarados numa nova perspectiva: a de que podem ser o mais adequado para promover a resolução do problema.

A técnica adotada para solução do conflito também deve estar em sintonia com o direito material discutido. Como exemplo o conflito familiar, em que há uma relação estremecida, o debate judicial agravará o desentendimento, forçando que as partes se coloquem umas contra as outras. Além disso, a relação familiar continua após o encerramento do processo, devendo ser preservada (CÂMARA, 2017, p. 18). Verificando tal possível prejuízo à relação familiar, o legislador aproveitou a oportunidade de reestabelecer laços, e previu no art. 694 do Código de Processo Civil que "Nas ações de família, todos os esforços serão empreendidos para a solução consensual da controvérsia [...]".

Portanto, todos esses mecanismos, ao serem compatibilizados com o direito em voga, ao serem aplicados tanto no curso do processo judicial como fora dele, são capazes de promover a concretização do acesso à justiça, permitindo que as partes tenham maior participação na decisão e a obtenham de forma mais rápida.

O art. 174 do Código faz parte da Seção V "Dos Conciliadores e Mediadores Judiciais", dentro do Capítulo sobre auxiliares da justiça, e traz uma obrigação à União, aos Estados, ao Distrito Federal e aos Municípios de criar câmaras de mediação e conciliação para solução consensual de conflitos no âmbito administrativo, porquanto utilizou o verbo "criarão", sem conotação opcional. ${ }^{2}$

Outrossim, tem-se a audiência do art. 334 como inovação legislativa do Código, que consiste em uma tentativa de conciliação e mediação, que são formas autocompositivas de resolução de conflitos. Um dos destaques é a posição da audiência no rito procedimental, que é determinante para seu objetivo, em que o réu não é citado para defender-se, mas sim para comparecer à audiência (diferentemente da audiência preliminar do Código anterior). Cumprindo o preâmbulo da Constituição Federal de 1988, que traz entre os pilares do Estado a solução pacífica das controvérsias, Marinoni, Arenhart e Mitidiero (2017, p. 285) entendem que

\footnotetext{
${ }^{2}$ O Código, entretanto, apenas institucionalizou e tornou geral o que já estava sendo praticado em âmbito federal por meio da Câmara de Conciliação e Arbitragem da Administração Federal - CCAF desde 2007 (CUÉLLAR, MOREIRA, 2018, s.p.).
} 
desestimula a cultura do litígio e fomenta a do diálogo, promovendo tentativa de solução no início do processo.

Leila Cuéllar e Egon Bockmann Moreira (2018, s.p.) são enfáticos ao defender que a audiência do art. 334 não pode ser unilateralmente dispensada pelo magistrado apenas pelo fato de a Administração Pública ser parte no processo, o que seria contra legem, pois o Código tem a audiência como condição prévia ao desenvolvimento do processo. Entende-se ser entendimento correto, em vista do que se apresenta nesta pesquisa: os métodos autocompositivos são plenamente compatíveis com a participação da Administração Pública.

\subsection{Legislação Especial Referente à Administração Pública}

Com relação ao escopo do presente estudo, que é a utilização dos métodos de composição de conflitos para a Administração Pública, já existiam algumas disposições legais que permitem a utilização de meios alternativos à solução judicial, como o art. 23-A, inserido em 2005 na Lei de concessão e permissão de prestação de serviços públicos, a Lei 8.997/1995: “Art. 23-A. O contrato de concessão poderá prever o emprego de mecanismos privados para resolução de disputas decorrentes ou relacionadas ao contrato, inclusive a arbitragem [...]"; e o art. 11, inciso III, da Lei das parcerias público-privadas, a Lei 11.079/2004, que prevê o mesmo, e na Lei 12.462/2011, a Lei do RDC (Regime Diferenciado de Contratação), no art. 44-A incluído em 2015 (POZZO, FECURI, 2017, p. 240-241).

Outro exemplo de consensualidade pode ser encontrado na Lei Complementar 73/2010, a Lei Orgânica da Advocacia-Geral da União, que foi modificada em 1997 pela Lei 9.469 prevendo um valor máximo para que houvesse transação em juízo (LOUBET, 2009, p. 117). O destaque é que essa lei foi modificada em quase sua totalidade pela Lei 13.140/2015, ampliando as possibilidades antes previstas e aumentando o teto de valores.

Por fim, destaca-se também a Lei 8.429/1992, a Lei de Improbidade Administrativa, mas no sentido contrário, devido ao art. $17, \S 1^{\circ}$, expressamente vedar transação, acordo ou conciliação nas ações de improbidade administrativa. Muito embora tenha havido uma tentativa de impedir essa vedação, com a revogação pela Medida Provisória 703/2015, esta teve sua vigência encerrada sem a conversão em lei, retornando a vedação a vigorar. 
Observa-se que as previsões normativas constam de leis especiais ${ }^{3}$, e indicam meios genéricos, acordos ou a arbitragem, sem fazer referência expressa à mediação ou conciliação, e até 2015, não havia regulamentação na Lei de Arbitragem referente à Administração Pública. Destarte, todo esse arcabouço legal ainda não era suficiente para que a Administração Pública adotasse as formas alternativas como preferenciais, apesar de todos os benefícios que poderiam trazer, esbarrando tanto na falta de regulamentação específica (haviam apenas os permissivos genéricos acima) e no dogma da indisponibilidade do interesse público, barreiras que serão abordadas em seguida.

\section{LEI DE MEDIAÇÃO E A AUTOCOMPOSIÇÃO NA ADMINISTRAÇÃO PÚBLICA}

A Lei 13.140/2015 é considerada pela doutrina como a instauração de uma nova ordem sobre o tema, apesar de já haver menções aos meios alternativos de solução de conflito em outros diplomas legais ou atos normativos como a Resolução do CNJ. Por exemplo, Augusto Neves Dal Pozzo e Ana Cristina Fecuri exaltam a Lei como uma referência na regulação da mediação tanto em aspectos para particulares como para a Administração Pública (2017, p. $243) .^{4}$

Isto posto, a Lei de Mediação, como é chamada a Lei 13.140/2015, traz a definição de mediação (art. $1^{\circ}$, parágrafo único), seus princípios informadores (art. $2^{\circ}$ ), seu objeto (art. $3^{\circ}$ ), quem serão mediadores (arts. $4^{\circ}$ a 13 ), bem como o procedimento da mediação, seja ela extrajudicial ou no curso do processo judicial (arts. 14 a 29), e aspectos da confidencialidade (arts. 30 e 31). O art. 32 e seguintes tratam da "autocomposição de conflitos em que for parte pessoa jurídica de direito público", rompendo a desconfiança e receio com a qual era vista pelo legislador, que não impôs teto de valor ou restrição específica de matéria.

\subsection{Rompimento da Barreira do Interesse "Indisponível"}

\footnotetext{
${ }^{3}$ Roberta Maria Rangel (2017, p. 275) ainda aponta outras leis administrativas especiais, como a Lei 9.472, de 16.07.1997 (Lei Geral das Telecomunicações), a Lei 9.478, de 06.08.1997 (Lei do Petróleo), Lei 10.233, de 05.06.2001 (Lei dos Transportes Aquaviário e Terrestre) e a Lei 11.909, de 04.03.2009 (Lei do Transporte de Gás Natural). Salienta-se que tratam de serviços públicos com cunho econômico e a lei aprofunda bastante em aspectos contratuais da prestação do serviço.

${ }^{4}$ No mesmo sentido, a obra organizada por Durval Hale, Humberto Dalla Bernardina de Pinho e Trícia Navarro Xavier Cabral, nomeia a Lei 13.140 de 2015 como "o marco legal da mediação no Brasil", inaugurando a ordem do que se considera o "direito consensual" (2016, s.p.).
} 
A Lei de Mediação vem em conjunto com outros dois importantes marcos: a Lei 13.129/2015, que expressamente torna ampla a arbitragem para a Administração Pública, e o Código de Processo Civil, que estimula as formas alternativas de solução de conflitos, pois, conforme o previamente exposto sobre o Código, nas suas normas fundamentais foram celebradas as formas alternativas de solução de conflito, de forma muito impactante, sob a referência do acesso à justiça (art. $3^{\circ}$, caput).

Em seu art. 174, impõe-se um dever à União, aos Estados, ao Distrito Federal e aos Municípios de criar câmaras de mediação e conciliação para solução consensual de conflitos no âmbito administrativo - trata-se de um dever a ser implementado pelos entes federados. Temse, logo, que a mediação e conciliação públicas são alternativa possíveis à solução judicial. Contudo, o emprego das técnicas deve observar alguns limites, mais restritos que a mediação e conciliação para particulares, como afirmam Luiz Guilherme Marinoni, Sérgio Cruz Arenhart e Daniel Mitidiero ao comentar sobre o art. 174 (2017b, p. 308):

\footnotetext{
Nesse campo, porém, os limites de sua incidência estão condicionados aos limites em que é possível a autocomposição no âmbito dos interesses públicos. Mesmo em casos em que o interesse não admita autocomposição, porém, é possível o emprego das técnicas para, se for o caso, a celebração de termo de ajustamento de conduta (em que o objetivo é apenas a oferta de prazo para a correção do comportamento ilegal - art. $5^{\circ}$, § $6^{\circ}$, Lei $\left.7.347 / 1985\right)$, ou ainda para a solução de conflitos envolvendo exclusivamente órgãos e entidades da administração pública.
}

Como é da essência da autocomposição, há uma maior autonomia dos envolvidos, que realizam espécie de negociação para que se atinja o resultado mais adequado. Passa-se a pensar se é possível a Administração Pública, por meio de seus órgãos e entidades, desenvolver uma solução ao problema em conjunto com o particular.

Destarte, a consensualidade administrativa tornou-se tópico bastante discutido, visto que já não se pode conceber um modelo de Estado em que a sociedade não participe das suas decisões, e a "Administração Consensual" tornou-se um novo modelo de gestão pública (LOUBET, 2009, p. 82). Abriu-se uma porta para formas de participação popular e democrática, em que "A Administração passa a ter a atividade de mediação para dirimir e compor conflitos de interesses entre as várias partes ou entre estas e a Administração. Daí decorre um novo modo de agir, [...] como atividade aberta à colaboração dos indivíduos. ” (MEDAUAR, 1992, p. 202). 
Do mesmo modo, não se vislumbra ideal justiça e processo sem que a Administração Pública, responsável por gerenciar o interesse público e da coletividade, possa usufruir mais livremente dos instrumentos de composição de conflito e dos benefícios que podem trazer. É preciso, enfim, compatibilizar a autocomposição com a tutela do interesse público.

O interesse público, de fato, é regido pela característica da indisponibilidade, pois a Administração Pública não é sua titular, e sim mera gestora, devendo sempre buscar atingir os interesses da sociedade e não seus próprios (MELLO, 2003, pp. 56-57), o que, contudo, não constitui impedimento para a utilização de tais instrumentos, já que são norteados pela concretização de direito, pela dignidade humana, acesso à justiça, e por valores constitucionais.

É nítido que o Estado cada vez mais se utiliza de mecanismos privados para desenvolver suas atividades, aponta Floriano de Azevedo Marques Neto (2002, p. 135), como no uso do instrumento contratual, a criação de empresas públicas e sociedades de economia mista, e atualmente até tem participação societária em empresas privadas e contribui no fomento de algumas atividades privadas.

O emprego de métodos alternativos para resolução de conflitos se conecta com essa realidade, já inseridos nas anteriormente mencionadas leis de concessão, permissão, parceriaspúblico privadas, RDC, agora se está diante da sua generalização (em uma longínqua comparação, é como ocorreu em 1994 com a universalização da tutela antecipada). Com as leis de 2015, a Administração Pública tem mais liberdade para adotar outras técnicas que solucionem as controvérsias de modo mais rápido, eficaz e com menor desgaste.

Sobre a quebra de paradigma, comenta José dos Santos Carvalho Filho (2017, p. 214):

Cuida-se, à evidência, de estimular o princípio do consensualismo na Administração, não somente em respeito ao postulado da celeridade e economicidade administrativas, como também para reduzir o ânimo de litigância em que se tem inspirado o Poder Público, com grande prejuízo para este e para o particular. [grifo do autor]

Especialmente a respeito da mediação, que trata a Lei 13.140/2015, a tutela do interesse público não é incompatível, transigir e ceder ao realizar um acordo não implica em deixa-lo desprotegido. Em situações específicas, atender ao interesse público é adotar uma solução que beneficie a coletividade e ao mesmo tempo beneficie o particular com quem se negocia. Justamente, conclui Floriano de Azevedo Marques Neto (2002, p. 154), que "o atendimento do interesse privado (mormente quando este se reveste de caráter meta-individual), hodiernamente, é, no mais das vezes, forma única de consagração do interesse público". 
Não deixou o interesse público de ser revestido de indisponibilidade, e sim deixa de ser um conceito jurídico único e inflexível, pois o administrador pode estar diante de situações que permitam acordos. Roberta Maria Rangel faz uma distinção (2017, p. 264), asseverando os casos em que não cabe a autocomposição por tratar de interesses denominados "primários", aqueles fora do mercado, enquanto os interesses denominados "secundários" admitem a autocomposição, já que "têm expressão patrimonial, estão no mercado, são disponíveis, podem ser objetos de contratação".

Sob a luz do entendimento da doutrina, é patente a necessidade de haver limites quanto ao alcance do poder de negociação conferido às pessoas da Administração Pública, e a Lei 13.140/2015 indica, no art. $3^{\circ}$, apenas será objeto de mediação o conflito sobre "direitos disponíveis ou sobre direitos indisponíveis que admitam transação", sendo que envolvendo direitos indisponíveis transigíveis, o consenso depende de homologação judicial, ouvido o Ministério Público (art. $3^{\circ}, \S 2^{\circ}$, da Lei 13.140/2015).

Acerca dos direitos indisponíveis sujeitos a transação, Antônio Carlos Ozório Nunes (2016, p. 67) define como "aqueles sobre os quais o titular não pode dispor, em razão do interesse ou da finalidade pública [...]. São os direitos fundamentais absolutos, intransferíveis e irrenunciáveis", mas sobre os quais a Administração poderá "transacionar para acertar valores, divisão de responsabilidades". Compreende-se, nesse diapasão, que a composição recairá sobre elementos não nucleares do direito ou interesse, mas questões acessórias, instrumentais, que não prejudiquem sua proteção.

Admitida a existência, portanto, de interesses com aspectos que não são absolutamente indisponíveis e intocáveis, poderá haver a composição, e, havendo processo judicial, deve ocorrer a audiência do art. 334, como comentado no tópico correspondente, podendo ocorrer a dispensa apenas se a demanda versar sobre direitos indisponíveis ou que não admitam transação (CUÉLLAR, MOREIRA, 2018, s.p.), caso contrário, é dever do magistrado intimar as partes para a tentativa de autocomposição.

E, no que tange ao debate sobre princípios administrativos, a solução consensual não os contraria. Sobretudo, com a edição da Lei 13.140/2015, a mediação para a Administração Pública encontra amparo neles. Luciane Moessa de Souza e Cristina Ayoub Riche (2016, p. 178) colocam a mediação em harmonia com o princípio da legalidade e as demais regras de atuação administrativa, tendo em vista que os acordos realizados pelos órgãos e entidades públicas devem “deixar claro por que determinada solução é o caminho mais adequado para 
resolver o conflito, sob o ponto de vista da legalidade, da eficiência (que compreende a economicidade) e todos os demais parâmetros que devem reger a atuação de entes públicos."

Desse modo, cumprindo as condições legais quanto ao objeto, fundamentação, forma, não há óbice para que a Administração Pública submeta seus conflitos à mediação.

\subsection{Apontamentos Sobre o Art. 32 e Seguintes da Lei 13.140/2015}

O Capítulo II da Lei de Mediação se intitula "Da Autocomposição de Conflitos em que for Parte Pessoa Jurídica de Direito Público". Ainda que se considere ter ocorrido uma evolução positiva no entendimento sobre a autocomposição na esfera pública, ainda haveriam alguns problemas, que devem ser pontuados.

O legislador, no art. 32 da Lei 13.140/2015 reitera o art. 174 do Código de Processo Civil, sobre a criação de câmaras próprias para resolução de conflitos, que serão órgãos destinados a prevenção e solução extrajudicial de controvérsias.

Na ótica de Roberta Maria Rangel (2017, p. 267) perpetuou-se a burocratização da mediação, que poderia ter sido simplificada se mantido o projeto original do Senado, em que não se previa a criação de câmaras próprias para a solução de conflitos. O texto aprovado e que vigora, prevê que cada ente deverá dispor de regulamento próprio sobre a organização e funcionamento das câmaras. Assim sendo, a aplicabilidade fica restrita, dependendo da regulamentação federal, estadual ou municipal, muito embora o art. 33 permita o uso do procedimento geral de mediação da própria lei.

A redação do $\S 2^{\circ}$ do art. 32 dispõe que a submissão do conflito às câmaras do caput será facultativa, e os casos admissíveis caberão ao regulamento de cada ente federado prever. Contudo, fica autorizado pela Lei 13.140/2015 que as câmaras sejam competentes para (i) dirimir conflitos entre órgãos e entidades do mesmo ente federado; (ii) avaliar a admissibilidade de composição de controvérsia entre particular e pessoa jurídica de direito público daquele ente; (iii) celebrar Termo de Ajustamento de Conduta - TAC; e (iv) prevenção e resolução de conflitos sobre equilíbrio econômico-financeiro de contratos $\left(\S 5^{\circ}\right)$.

As competências que se conferem às câmaras, conforme a Lei de Mediação, coadunam-se com as definidas no art. 174 do Código de Processo Civil (POZZO, FECURI, 2017, p. 246). 
Por fim, a respeito do resultado da mediação realizada nos órgãos, diz o $\S 3^{\circ}$ que, havendo o acordo, este será reduzido a termo e constituirá título executivo extrajudicial. Restando infrutífera as tentativas de mediação, por conseguinte lógico será deflagrado uma demanda judicial, em que não se impede nova tentativa de composição.

O parágrafo único do art. 33 da Lei de Mediação atribui à Advocacia Pública de cada um dos entes federados a possibilidade de instaurar procedimento de mediação coletiva de conflitos sobre prestação de serviços públicos.

A mediação coletiva é amplamente utilizada em matéria trabalhista, em que conflitos coletivos são comuns e podem ser mais facilmente resolvidos, ao contrário do que ocorreria com diversas ações individuais, que até poderiam ter resultados conflitantes e sem isonomia na solução apresentada.

A leitura do art. 34 é simples e direta, dispôs o legislador que "A instauração de procedimento administrativo para a resolução consensual de conflito no âmbito da administração pública suspende a prescrição."

Avançando ao art. 35, “As controvérsias jurídicas que envolvam a administração pública federal direta, suas autarquias e fundações poderão ser objeto de transação por adesão, [...]". Consoante André Luis Bergamaschi (2015, p. 164), essa nomenclatura "designa uma forma de resolução de conflitos repetitivos, que têm por base a mesma discussão jurídica e, de um dos lados, o mesmo ente público".

A transação por adesão prevista na Lei 13.140/2015 inaugura seção específica sobre conflitos com a Administração Pública Federal Direta, suas Autarquias e Fundações. Os Estados deverão possuir regulamentação própria para prever o método.

De acordo com a lei, tem como requisitos e fundamentos a prévia autorização do Advogado-Geral da União, e ocorre com base na jurisprudência pacífica do Supremo Tribunal Federal ou de tribunais superiores (inciso I) ou em parecer do Advogado-Geral da União aprovado pelo Presidente da República (inciso II). A doutrina entende que se admite, no inciso I, uso das Súmulas da própria Advocacia-Geral da União (RANGEL, 2017, p. 271).

O método da adesão já foi utilizado pela Caixa Econômica Federal para extinguir demandas sobre planos econômicos que prejudicaram ativos financeiros de poupança. A transação resultou em acordo positivado nos arts. $4^{\circ}$ a $7^{\circ}$ da Lei Complementar 110/2001 ,

\footnotetext{
${ }^{5} \mathrm{O}$ termo de adesão foi questionado judicialmente em inúmeras ações, mas o Supremo Tribunal Federal validou o acordo, e editou a Súmula Vinculante 1: "Ofende a garantia constitucional do ato jurídico perfeito a decisão que, sem ponderar as circunstâncias do caso concreto, desconsidera a validez e a eficácia de acordo constante de termo de adesão instituído pela Lei Complementar n ${ }^{\circ}$ 110/2001.”
} 
permitindo que o titular da conta prejudicada firmasse o Termo de Adesão para receber valores e corrigir a defasagem em contas vinculadas ao FGTS (BERGAMASCHI, 2015, p. 165).

A adesão permite que não precise se instaurar um processo de composição para cada prejudicado, e sim realizar um acordo que se possa realizar a adesão posteriormente. Contudo, o particular que adere ao termo não participou da formação da solução, o que não corresponde à essência do instituto da transação dentro da lei de mediação. André Luis Bergamaschi (2015, p. 166) pondera essa questão, mas enquadra a prática como transacional, visto que depende de aceitação (bilateral), e via de regra, a Administração faz uma proposta em que abre mão de algo em troca da aceitação do particular.

Por sua vez, a opinião de Augusto Neves Dal Pozzo e Ana Cristina Fecuri (2017, p. 241) segue entendimento inicial, que esse método "não permite que as partes negociem”, pois há uma simples habilitação dos interessados para aderirem aos termos propostos - sempre com manifestação da Advocacia-Geral da União.

De qualquer modo, a transação por adesão necessita de fiscalização para proteger o particular fora da negociação, para evitar a judicialização posterior, e voltar à problemática de ajuizamento excessivo de demandas que tentava ser solucionada com os métodos alternativos.

Dando seguimento aos dispositivos da Lei 13.140/2015, os arts. 36 e 37 tratam da atuação da Advocacia-Geral da União na composição extrajudicial do conflito.

O primeiro dispõe sobre a composição extrajudicial entre órgãos ou entidades de direito público que integram a administração pública federal, e utiliza a expressão "a Advocacia-Geral da União deverá realizar composição extrajudicial do conflito, observados os procedimentos previstos em ato do Advogado-Geral da União" - desse modo, a Lei de Mediação é expressa em expor esse dever.

Existe, desde 2007, a Câmara de Conciliação e Arbitragem da Administração Federal - CCAF, que foi instituída pelo Ato Regimental Advocacia-Geral da União no 5, de 27 de setembro de 2007 (CUÉLLAR, MOREIRA, 2018, s.p.). A Câmara já estava em funcionamento e já tem vários casos solucionados por meio da autocomposição ${ }^{6}$, tendo sido ampliada sua competência ao longo dos anos, e inserida na estrutura da Consultoria-Geral da União (RANGEL, 2017, p. 268). Desde 2015, é o órgão responsável por realizar essa composição, obrigatória por força de lei.

\footnotetext{
${ }^{6}$ A Advocacia-Geral da União considera como leading case o acordo que resultou da mediação que envolveu 6 hospitais públicos federais e uma empresa privada. Sobre o caso, ver: http://www.agu.gov.br/page/content/detail/id_conteudo/464595
} 
O segundo dá a faculdade aos demais entes federados (Estados, Distrito Federal e Municípios) e as pessoas da administração pública federal indireta (autarquias, fundações públicas, empresas públicas e sociedades de economia mista federais), de submeter à Advocacia-Geral da União os litígios que possuem com órgãos ou entidades da administração pública federal, para fins de composição extrajudicial.

Posteriormente, o art. 38 trata de composição de débitos tributários relativos a tributos administrados pela Secretaria da Receita Federal do Brasil ou a créditos inscritos em dívida ativa da União, e limita a abrangência da mediação e outros métodos de composição.

Por exemplo, veda celebração de Termo de Ajustamento de Conduta - TAC e restringe os sujeitos que podem submeter seus litígios à análise de admissibilidade. Quanto aos sujeitos, delimita que poderão ser partes os órgãos da administração pública federal direta, suas autarquias e fundações, enquanto fica impedidas de ser partas particulares e empresas públicas, sociedades de economia mista e subsidiárias que explorem atividade econômica de produção ou comercialização de bens ou de prestação de serviços em regime de concorrência (RANGEL, 2017, p. 272).

Uma ressalva é feita no parágrafo único do artigo, segundo o qual este art. 38 não afasta a competência do Advogado-Geral da União prevista em alguns dispositivos da Lei Complementar 73/1993, e da Lei 9.469/1997, que tratam, entre outros, dos poderes de desistir e transigir nas ações de interesse da União, prevenir e dirimir as controvérsias entre os órgãos jurídicos da Administração Federal (Lei Complementar 73/1993) e fazer acordos ou transações para prevenir ou terminar litígios, inclusive judiciais (Lei 9.469/1997).

$\mathrm{O}$ art. 39 expressa o que Roberta Maria Rangel entende como "norma preventiva de litígios" (2017, p. 273), cabendo ao Advogado-Geral da União autorizar “a propositura de ação judicial em que figurem concomitantemente nos polos ativo e passivo órgãos ou entidades de direito público que integrem a administração pública federal”.

Por fim, o art. 40 aborda a responsabilidade dos agentes públicos que participarem da composição extrajudicial, os quais "somente poderão ser responsabilizados civil, administrativa ou criminalmente quando, mediante dolo ou fraude, receberem qualquer vantagem patrimonial indevida, permitirem ou facilitarem sua recepção por terceiro, ou para tal concorrerem”, consistindo em responsabilidade subjetiva. Interpretam corretamente Augusto Neves Dal Pozzo e Ana Cristina Fecuri (2017, p. 241) que, além de premiar a boa-fé, o art. 40 tenta afastar os agentes de represálias pela atuação nos processos de composição. 
A lei encerra suas disposições alterando outras legislações, incluindo normas a respeito da atuação da Advocacia Pública, fechando o diploma que consolida a regulamentação da mediação - e outros métodos de solução de conflito, pois, de acordo com Roberta Maria Rangel (2017, p. 274), de forma relapsa a redação da lei não uniformizou a nomenclatura dos conflitos e procedimentos.

\section{CONSIDERAÇÕES FINAIS}

A via judicial é o tradicional método heterocompositivo de resolução de conflitos, que, entretanto, não é mais tão eficaz como se propôs, em face do aumento da demanda, da lentidão processual, dos altos custos às partes e ao Estado, e do desgaste que gera, uma vez que havia se desenvolvido uma cultura de litígio e judicialização, ainda presente e que deve ser modificada.

Observa-se que ocorreu uma evolução legal e doutrinária sobre os meios alternativos de solução de conflitos há cerca de 3 décadas, impulsionados pela experiência americana do “Tribunal Multiportas" e com o reconhecimento do acesso à justiça formal (meios) e material (resultados). A proposta é alterar a cultura do litígio para a do diálogo, otimizando a solução de conflitos em todos os aspectos citados.

Essa evolução se destaca com a edição do Código de Processo Civil de 2015 e a Lei de Mediação do mesmo ano, que celebram os meios alternativos como vertentes do acesso à justiça. Por certo, a legislação brasileira possui, ainda, diversos outros exemplos de previsão de meios alternativos de resolução de conflito, seja negociação, conciliação, mediação ou arbitragem. Ademais, essas normas referem-se ao mais diversos tipos de matérias, como no âmbito penal, cível, família, trabalhista e também a respeito da atuação da Administração Pública.

Justamente neste ponto que pairou o propósito do estudo, a autocomposição em conflitos em que a Administração Pública, seus órgãos e entidades, são parte. Esse cenário observa a compatibilidade com a proteção do interesse público e a regulamentação necessária, pois devem haver contornos próprios. Com a Lei de Mediação, a Lei 13.140/2015, surge uma gama de dispositivos legais específicos sobre a submissão de conflitos com as pessoas da administração pública à composição, os quais foram comentados nos seus principais aspectos.

A Lei 13.140/2015 acompanhou a prática que estava ocorrendo de forma interna em diversos órgãos públicos, especialmente nas Advocacias Públicas. O que se espera com esse 
novo revestimento legal é uma evolução e criação de novos órgãos, destinados a instrumentalizar a composição pública nos limites e condições estabelecidas, sem, entretanto, consistir em mais uma lei que permite a criação de mais órgãos e cargos sem cumprir seu propósito com eficiência. Colocar em prática a consensualidade nos conflitos com a Administração Pública é parte da tutela do interesse público.

\section{REFERÊNCIAS}

ALMEIDA, Rafael Alves de. ALMEIDA, Tania. CRESPO, Mariana Hernandez. Tribunal multiportas: investindo no capital social para maximizar o sistema de solução de conflitos no Brasil. Rio de Janeiro: Editora FGV, 2012.

BRASIL. Lei 13.105, de 16 de março de 2015. Código de Processo Civil.

BRASIL. Lei 13.140, de 26 de junho de 2015. Dispõe sobre a mediação entre particulares como meio de solução de controvérsias e sobre a autocomposição de conflitos no âmbito da administração pública.

BERGAMASCHI, André Luis. Resolução de conflitos envolvendo a administração pública por mecanismos consensuais. 2015. Dissertação (Mestrado em Direito Processual) Faculdade de Direito, Universidade de São Paulo, São Paulo, 2015. Disponível em: <http://www.teses.usp.br/teses/disponiveis/2/2137/tde-21032016-140915/pt-br.php>. Acesso em: 16 de julho de 2018.

CÂMARA, Alexandre Freitas. O novo processo civil brasileiro. 3. ed. São Paulo: Atlas, 2017.

CAPPELLETTI, Mauro; GARTH, Bryant. Acesso à justiça. 1 ed. Porto Alegre: Sergio Fabris, 1988.

CINTRA, Antônio Carlos Araújo; GRINOVER, Ada Pelegrini; DINAMARCO, Cândido Rangel. Teoria geral do processo. 31. ed. São Paulo: Malheiros, 2015.

CONSELHO NACIONAL DE JUSTIÇA. Justiça em Números 2017: (ano base 2016). Brasília: Conselho Nacional de Justiça, 2017. Disponível em: <http://www.cnj.jus.br/programas-e-acoes/pj-justica-em-numeros> Acesso em 15 de julho de 2018.

CONSELHO NACIONAL DE JUSTIÇA. Resolução no $\mathbf{1 2 5}$, de 29 de novembro de 2010. Dispõe sobre a Política Judiciária Nacional de tratamento adequado dos conflitos de interesses no âmbito do Poder Judiciário e dá outras providências. Brasília: 2010. Atualizado com a Emenda $n^{\circ}$ 01/2013 e Emenda ${ }^{\circ}$ 02/2016. Disponível em: <http://www.cnj.jus.br/busca-atosadm?documento=2579> Acesso em: 16 de julho de 2018 . 
CUÉLLAR, Leila. MOREIRA, Egon Bockmann. Administração Pública e mediação: notas fundamentais. Revista de Direito Público da Economia - RDPE, Belo Horizonte, ano 16, n. 61, jan./mar. 2018. Disponível em:

<http://www.bidforum.com.br/PDI0006.aspx?pdiCntd=250845> Acesso em: 30 maio 2018.

FERREIRA, Pinto. Técnica legislativa como a arte de redigir leis. Revista Inf. Legisl. Ano 23, n. 89. Brasília: jan/mar. 1986, p. 169-198. Disponível em: <https://www2.senado.leg.br/bdsf/bitstream/handle/id/181674/000421282.pdf?sequence=3> Acesso em: 17 de julho de 2018.

HALE, Durval. PINHO, Humberto Dalla Bernardina de. CABRAL, Trícia Navarro Xavier. (Org.) O marco legal da mediação no Brasil: comentários à lei 13.140, de 26 de junho de 2015. São Paulo: Atlas, 2016.

LOUBET, Wilson Vieira. O princípio da indisponibilidade do interesse público e a administração consensual. 1 ed. Brasília: Editora Consulex, 2009.

MARINONI, Luiz Guilherme. ARENHART, Sergio Cruz. MITIDIERO, Daniel. Novo curso de processo civil: teoria do processo civil, volume 1. 3 ed. São Paulo: Editora Revista dos Tribunais, 2017.

MARINONI, Luiz Guilherme. ARENHART, Sergio Cruz. MITIDIERO, Daniel. Novo código de processo civil comentado. 3 ed. São Paulo: Editora Revista dos Tribunais, 2017b.

MARQUES NETO, Floriano de Azevedo. Regulação Estatal e Interesses Públicos. 1 ed. São Paulo: Malheiros, 2002.

MEDAUAR, Odete. O direito administrativo em evolução. 1 ed. São Paulo: Revista dos Tribunais, 1992.

MEDINA, José Miguel Garcia. Direito processual civil moderno. 3 ed. São Paulo: Editora Revista dos Tribunais, 2017.

MELlO, Celso Antônio Bandeira de. Curso de direito administrativo. 15 ed. São Paulo: Malheiros Editores, 2003.

NUNES, Antônio Carlos Ozório. Manual de mediação: guia prático da autocomposição. 1 ed. São Paulo: Editora Revista dos Tribunais, 2016.

POZZO, Augusto Neves Dal. FECURI, Ana Cristina. Panorama acerca da nova lei de mediação e seus reflexos na administração pública. In: Arnoldo Wald; Marçal Justen Filho; Cesar Augusto Guimarães Pereira. (Org.). O Direito Administrativo na Atualidade. Estudos em homenagem ao centenário de Hely Lopes Meirelles. 1ed.São Paulo: Malheiros Editores, 2017, v. 1 , p. $240-250$.

RANGEL, Roberta Maria. As regras da lei da mediação (lei 13.140/2015) para a administração pública. In: ROCHA, Caio Cesar Vieira. SALOMÃO, Luis Felipe (Coord.) Arbitragem e mediação: a reforma da legislação brasileira. 2 ed. São Paulo: Atlas, 2017. p. 259-275. 
SOUZA, Luciane Moessa de. RICHE, Cristina Ayoub. Das câmaras de mediação. In: ALMEIDA, Diogo Assumpção Rezende de. PANTOJA, Fernanda Medina. PELAJO, Samantha (Orgs) A mediação no novo código de processo. 2 ed. Rio de Janeiro: Forense, 2016. p. 176-218.

THEODORO JÚNIOR, Humberto. Curso de direito processual civil - Teoria geral do direito processual civil, processo de conhecimento e procedimento comum. Vol. 1. 56. ed. Rio de Janeiro: Forense, 2015. 